einen, großen, unteilbaren dār al-islām, dessen Verkörperung das Osmanische Reich darstellte; wenn ein Staat sich gegen dieses wandte, wurden die Regeln über Rebellion und Apostasie auf ihn angewandt.

Dagmar Hohberger

Goran Melander/Peter Nobel (Herausg.)

\title{
International Legal Instruments on Refugees in Africa
}

Scandinavian Institute of African Studies, Uppsala, 1979, 413 S., Skr. 250,-

Ein von den schwedischen Juristen Melander und Nobel herausgegebener Sammelband zu völkerrechtlichen und innerstaatlichen Rechtsproblemen, die die prekäre Lage von zur Zeit rund vier Millionen Flüchtlingen in Afrika auf werfen, ist kürzlich in dieser Zeitschrift vorgestellt worden ${ }^{1}$. Dieselben Autoren legen nun einen Band mit Dokumenten zu den völkerrechtlichen Aspekten des Themas vor, der in Auswahl und Ausstattung nur wenig Wünsche offenläßt. Angesichts der hohen Seitenzahl drängt sich sofort die Frage auf, welche Dokumente über die wenigen, speziell Afrika betreffenden völkerrechtlichen Verträge zum Flüchtlingsproblem hinaus aufgenommen worden sind: Die Autoren haben auch diejenigen „Legal Instruments“ einbezogen, die auf universeller Ebene zustandegekommen und für afrikanische Tatbestände relevant sind, so daß im Ergebnis nur wenig mehr als ein Viertel des Umfangs von ausschließlich auf Afrika bezogenen Dokumenten eingenommen wird. Jeder Text ist sowohl in englischer als auch in französischer Sprache abgedruckt und mit der offiziellen Fundstelle versehen; bei Verträgen sind Inkrafttreten und teilweise auch die Vertragspartner (nicht das Datum der Ratifikationen oder Beitritte) vermerkt.

Das Buch ist in vier Hauptteile gegliedert. Ein erster Teil enthält multilaterale Verträge, die unter der Ägide des Völkerbundes (hier jeweils nur Auszüge, die zur Definition des Flüchtlingsbegriffs von Interesse sind) und der Vereinten Nationen entstanden sind, ferner die „OAU Convention Governing the Specific Aspects of Refugee Problems in Africa“"vom 10. September 1969, die 1974 in Kraft getreten ist und die nach nunmehr zehn Jahren nur für 18 der 41 Unterzeichner-Staaten verbindlich ist: Ins Gewicht fällt besonders das Fehlen von Angola, Kenia, Libyen, Mozambik, Somalia. Teil II versammelt Auszüge von Verträgen, die wichtig für die Entscheidung der Frage sein können, wann eine Person als ,,verfolgt" (s. z. B. Art. 1 A, Nr. 2 der Flüchtlingskonvention vom 28. Juli 1951 i. V. m. Art. 1, Nr. 2 des Ergänzungsprotokolls vom 31. Januar 1967) anzusehen ist, indem sie Individualrechte normieren (neben den Menschenrechtspakten der Vereinten Nationen von 1966 etwa noch zwei Konventionen der Internationalen Arbeitsorganisation). Im dritten Teil finden sich Auszüge aus Verträgen zu Auslieferungsfragen bzw. zur Zuständigkeit zur strafrechtlichen Verfolgung fremder Staatsangehöriger (also zum sog. Internationalen Strafrecht), darunter ein Auslieferungsabkommen der Staaten der Arabischen Liga vom 14. September 1952. Der letzte Teil schließlich enthält Dokumente, die nicht per se völkerrechtlich verbindlich sind, gleichwohl teilweise durch ihre operativen Passagen handlungsanleitend gewirkt haben und wirken: Deklarationen und Resolutionen von UNO-Organen und solchen der OAU, Dokumente der Konferenz über das afrikanische Flüchtlingsproblem in Addis Abeba im Oktober 1967 und des Asian-African Legal Consultative Committee. Die Auswahl berücksichtigt generelle Erklärungen ebenso wie solche zu Einzelfällen (etwa zu den algerischen Flüchtlingen in Marokko und Tunesien Anfang der 60er Jahre); indirekt macht sie damit deutlich, wie unterschiedlich die beiden großen internationalen Organisationen in ihrer Resolutionspraxis

1 VRU 11 (1978), S. 445. 
vorgegangen sind: Nichteinmischungsprinzip und Furcht vor Bumerang-Effekten haben dazu geführt, daß die Organe der OAU sich fast durchweg nur allgemein mit dem Flüchtlingsproblem befaßt haben (signifikant etwa der Unterschied zur UNO, hier: Wirtschaftsund Sozialrat, in der Behandlung des sudanesischen Bürgerkrieges). Irreführend ist die Auswahl allerdings insofern, als sie den Eindruck erweckt, nur die UNO habe sich speziell mit Flüchtlingen aus den Apartheid-Ländern befaßt: Auch der Ministerrat der OAU hat einschlägige Revolutionen verabschiedet (z. B. die nicht mitabgedruckte ,,Resolution on Special Assistance to Southern African Refugees" $\left.{ }^{2 "}\right)$.

Das Erscheinen dieses durch einen Index gut erschließbaren Bandes bedeutet nicht nur für den Afrika-Spezialisten, sondern auch für den generell an Flüchtlingsfragen interessierten Völkerrechtler eine Erleichterung seiner Arbeit. Die beschwerliche Suche nach relevanten bilateralen Verträgen ist ihm freilich nach wie vor nicht abgenommen.

Philip Kunig

Peter C. W. Gutkind/Peter Waterman (Herausg.)

\section{African Social Studies}

\section{A Radical Reader}

Heinemann Educational Books Ltd., London, Ibadan, Nairobi, Lusaka, 1977, 481 S., $\$ 2,90$.

Dieser von dem Anthropologen Gutkind und dem Soziologen Waterman zusammengestellte Sammelband kann mit Fug als eine der erfreulichsten Neuerscheinungen der letzten Jahre auf dem Gebiet der Afrika-Forschung in einem weiteren Sinne bezeichnet werden: Auch wenn die Beiträge sämtlich als spezifisch politikwissenschaftliche, historische oder wirtschaftswissenschaftliche zu rubrizieren sind, bieten sie doch auch jedem anderen, der mit sozialwissenschaftlicher Fragestellung über Afrika arbeitet, wertvolle Informationen und Anregungen und nicht zuletzt auch dem Juristen, sofern ihn die Realität von Institutionen, deren Instrumentalisierung und Veränderung, die ,,Verfassungswirklichkeit“" interessieren. Internationale Beziehungen sind gänzlich ausgespart, was den innerafrikanischen Bereich anlangt; die Einflußnahmen auf Afrika von außerhalb des Kontinents werden gleichfalls nicht systematisch behandelt, sind freilich stets präsent: Es ist geradezu das Hauptanliegen der 40 Beiträge des Bandes, die derzeitige afrikanische Wirklichkeit in ihrer Prägung durch Kolonialismus und ihn ablösende Abhängigkeitsverhältnisse deutlich zu machen. Wichtig erscheint es, vor einem Mißverständnis des Begriffs, ,radical“ zu warnen, den die Herausgeber leitmotivisch in den Untertitel aufgenommen haben: Es publizieren hier nicht „Radikale“ in einem Sinne, der ihnen den Zugang zum öffentlichen Dienst in der Bundesrepublik Deutschland versperren würde. Vielmehr ist beabsichtigt, einer als unkritisch, vom ursprünglichen kolonisatorischen Interesse gespeist und in ihren Feststellungen erstarrt empfundenen Afrikanistik eine Wissenschaft gegenüberzustellen, die insbesondere bei der Auswahl ihrer Forschungsgegenstände berücksichtigt, was den Bevölkerungen der afrikanischen Staaten nützen, was ihnen ein emanzipiertes, menschenwürdiges Dasein ermöglichen könnte. Wissen, das diesem Ziel dienen kann, ist von diesen ,Radikalen“ gefragt, die sich zudem auf den ursprünglichen Wortsinn berufen, die ,,Wurzeln“ der Phänomene freilegen wollen. Daß nicht nur westliche Afrika-Literatur, sondern auch der Großteil der in Osteuropa betriebenen Forschung diesem Anspruch nichtgenügt, ist bekannt: Waterman nennt es

2 CM/Res. 547 (XXIX) vom Juli 1977 (Ministerratstagung in Libreville/Gabun). 